\title{
N-Oxidation of Pyrazines by Bromamine-B in Perchloric Acid Medium: Kinetic and Mechanistic Approach
}

\author{
Puttaswamy ${ }^{\star}$ and J. P. Shubha \\ Department of Chemistry, Central College Campus, Bangalore Lniversity, Bangalore-560 001, India \\ E-mail: prwami_chemóvahoo.com \\ Recerved Febriary 03, 2009, Accepted June 20,2009
}

\begin{abstract}
Kinetic investigations on the oxidation of pyrazine and four 2-substituted prrazines viz., 2-methylpyrazine, 2-ethylpyrazine, 2-methoxypyrazine and 2-aminopy razine by bromamine-B $(B A B)$ to the respective $N$-oxides have been studied in $\mathrm{HClO}_{4}$ medium at $303 \mathrm{~K}$. The reactions show identical kinetics being first-order each in [BAB] and [prtazine $]_{0}$, and a fractional- order dependence on $\left[\mathrm{H}^{-}\right]$. Effect of ionic strength of the medium and addition of benzenesulfonamide or halide ions showed no significant effect on the reaction rate. The dielectric effect is positive. The solvent isotope effect was studied using $\mathrm{D}_{2} \mathrm{O}$. The reaction has been studied at different temperatures and activation parameters for the composite reaction have been evaluated from the Arrhenius plots. The reaction showed $1: 1$ stoichiometry and the oxidation products of pyrazines were characterized as their respective $\mathrm{N}$-oxides. Under comparable experimental conditions, the oxidation rate of pyrazines increased in the order: 2-aminopyrazine > 2-methoxypyrazine $>2$-ethylpyrazine $>2$-methylpyrazine $>$ pyrazine. The rates correlate with the Hammett $\sigma$ relationship and the reaction constant $\rho$ was found to be -0.8 , indicating that electron donating centres enlance the rate of reaction. An isokinetic temperature of $B=333 \mathrm{~K}$, indicated that the reaction was enthalpy controlled. A mechanism consistent with the experimental results has been proposed in which the rate determining step is the formation of an intermediate complex between the substrate and the diprotonated species of the oxidant. The related rate law in consistent with observed results has been deduced.
\end{abstract}

Key Wonds: Pyrazines. Oxidation kinetics, Bromamine-B, Acid medium

\section{Introduction}

The chemistry of a class of N-metallo-N-haloarylsulfonamides. known as N-haloamines. attracted the attention of many investigators due to their diverse behaviour. Their versatile nature is attributed to their ability to act both as bases and

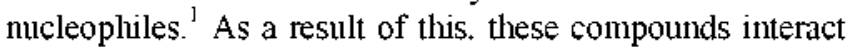
with a wide range of functional groups in aqueous. partially aqueous and non-aqueous media in presence of acids or alkalis. bringing about an array of molecular transformations. Monohaloamines in general undergo two electron change while dihaloamines act as four electron oxidants. The reduction products obtained are the respective sulfonamide and sodium chloride. ${ }^{2}$ The dominant members of this class of chlorocompounds are chloramine-T (CAT) and chloramine-B (CAB). A review of literature reveals that although the reaction of aromatic sulfonyl chloramines have been known and extensively investigated. ${ }^{1,3-7}$ there is not much of information ${ }^{8-11}$ available on the reaction of corresponding bromamines. bromamine- $T$ and bromamine-B. Sodium N-bromobenzenesulfonamide or bromamine-B (BAB: $\mathrm{C}_{6} \mathrm{H}_{5} \mathrm{SO}_{2} \mathrm{NBrNa} 1.5 \mathrm{H}_{2} \mathrm{O} \mathrm{BAB}$ ) has gained importance as a mild oxidant and it can be readily prepared by brominating $\mathrm{CAB}$. Bromamine- $\mathrm{B}$ is found to be a most potential oxidant among these N-haloamines. There are but a few reports ${ }^{12.13}$ on the kinetics of oxidation of organic substrates by $\mathrm{BAB}$ as compared to the studies with other haloamines as oxidants from mechanistic view point. For these reasons. it was felt interesting to investigate the mechanism of oxidations of the selected pyrazines with this reagent.

Pyrazines are important class of N-heterocycles. They be- have as tertiary amines and their properties resembles those of the pyridines. ${ }^{\text {it }} \mathrm{Py}$ razines possess unique and extremely potent flavor and aroma characteristics. ${ }^{15.16}$ Some of the derivatives of py razines find use as pharmaceutical intermediates. ${ }^{17}$ marking volatiles. ${ }^{18}$ antifungal and antiviral agents ${ }^{19}$ and hence they find extensive applications in flavor and pharmaceutical industries. Mild oxidation of pyrazines to $\mathrm{N}$-oxides find importance in synthetic organic chemistry and a considerable work has been carried out in this direction. ${ }^{20.24}$ These $\mathrm{N}$-oxides are widely used in the synthesis of various organic compounds and as bioreductive drugs. ${ }^{25.26}$ From the literature survey it was found there was no information available on the oxidation of pyrazines brought about by oxidants with regards to the kinetic and mechanistic points of view. Therefore. the mechanism and rate law for this redox system were obscure. Hence. the oxidation of pyrazines with these view points adds much to the knowledge of redox chemistry. These facts prompted us to undertake the title investigation.

Our preliminary kinetic studies revealed that the reactions between py razines and chloramines were too slow to be measured in neutral. acidic and alkaline media at ambient temperature. Further kinetic nus also indicated that $\mathrm{BAB}$ is an excellent oxidant in effecting controlled conversion of pyrazines to $\mathrm{N}$ oxides in presence of perclloric acid. Optimum conditions for the formation of $\mathrm{N}$-oxides have been established. In view of these observations. a sy stematic kinetic and mechanistic study of the oxidation of pyrazine and 2-substituted pyrazines namely 2-metlyylpyrazine, 2-ethylpyrazine. 2-methosy py razine and 2aminopy razine brought about by $\mathrm{BAB}$ in perchloric acid mediun at $303 \mathrm{~K}$ have been carried out. Objectives of the present 
investigations are to (i) compile kinetic data. (ii) establish optimum conditions effecting mild oxidation of pyrazines to $\mathrm{N}$ oxides. (iii) elucidate plausible mechanism. (iv) propose an appropriate kinetic model, (v) ascertain the reactive species. (vi) know the stoichiometry and to characterize the oxidation products. (vii) asses the relative rates of oxidation of pyrazines towards BAB. (viii) establish the isokinetic relationship from thermodynamic parameters and (ix) ascertain structure reactivity relationship.

\section{Experimental}

Materials. Bromamine-B was prepared ${ }^{77}$ by the partial debromination of dibromamine-B (DBB) as follows. Pure chlorine was bubbled through an aqueous solution of chloramine- $\mathrm{B}$ (30 g in $560 \mathrm{~mL}$ water) and liquid bromine ( $6 \mathrm{~mL}$ ) was added dropwise with constant stirring. A yellow precipitate of DBB formed was washed well with $\mathrm{H}_{2} \mathrm{O}$, filtered under suction, and dried in a vacuum desiccator. Dibromamine-B $(31.5 \mathrm{~g})$ was digested in batches with constant stirring in $50 \mathrm{~mL}$ of $4 \mathrm{~mol} \mathrm{dm}^{-3}$ $\mathrm{NaOH}$. The resulting mass was cooled in ice. filtered under suction, and the product (BAB) was dried over anhydrous calcium chloride. The purity of $\mathrm{BAB}$ was tested iodometrically through its active bromine content and its FT-IR spectrum. Aqueous solutions of $B A B$ were prepared, standardized whenever required by the iodometric method and preserved in brown bottles to prevent its photochemical deterioration. ${ }^{28}$ Pyrazines (Aldrich) of acceptable grades of purity were used without further purification. Fresh aqueous solutions of pyrazines were prepared whenever required. Heavy water $\left(D_{\curvearrowright} \mathrm{O}, 99.4 \%\right)$ for solvent isotope studies was obtained from Bhabha Atomic Research Center, India. All other chemicals used were of analy tical grade and double distilled water was used throughout the work.

Kinetic Pmcedure. Detailed kinetic runs were performed under pseudo-first order conditions of [pyrazine] $>>$ [oxidant]。 at a standard temperature of $30 \pm 0.1^{\circ} \mathrm{C}$ in glass stoppered py rex boiling tubes whose outer surface was coated black to eliminate photochemical effects if any. The $\mathrm{BAB}$ and requisite amounts of solutions of the pyrazine, $\mathrm{HClO}_{4}$ and water (to keep the total volume constant $(50 \mathrm{~mL})$ for all nins) were taken in separate boiling tubes and thermostatted at $30 \pm 0.1{ }^{\circ} \mathrm{C}$ till thermal equilibrium. The reaction was initiated by the rapid addition of a measured amount of $\mathrm{BAB}$ solution to the mixture and was shaken intermittently for uniform concentration. The progress of the reaction was monitored iodometrically by titration of unreacted $\mathrm{BAB}$ in known aliquots $(5 \mathrm{~mL}$ each) of the reaction mixture withdrawn at regular time intervals. The reactions were followed for more than two half-lives. The pseudo first-order rate constants $\left(k \mathrm{sec}^{-1}\right)$. calculated from the linear plots of $\log [B A B]$ vs time. were reproducible within $\pm 2-4 \%$. The regression analy sis of the experimental data was carried out on an $\mathrm{fx}-350 \mathrm{TL}$ scientific calculator to obtain the regression coefficient, $r$.

Stoichiometry. Reaction mixtures having different proportions of $\mathrm{BAB}$ and py razines were equilibriated at $303 \mathrm{~K}$ in presence of $5.0 \times 10^{-3} \mathrm{~mol} \mathrm{dm}^{-3} \mathrm{HClO}_{4}$ for $24 \mathrm{~h}$ and then analyzed. The unreacted $\mathrm{BAB}$ in the reaction mixture was determined iodometrically which indicated that one mole of pyrazine consumed one mole of $\mathrm{BAB}$ to give the corresponding $\mathrm{N}$-oxide. which is stoichiometrically represented as:

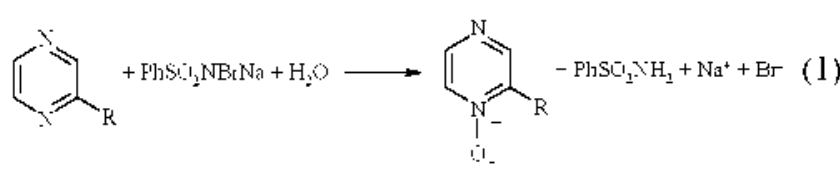

Here $\mathrm{R}=\mathrm{H}$ for pyrazine. $-\mathrm{CH}_{3}$ for 2-methy lpy razine, $-\mathrm{C}_{2} \mathrm{H}_{5}$ for 2-ethylpy razine. $-\mathrm{OCH}_{3}$ for 2 -methoxypyrazine and $-\mathrm{NH}_{2}$ for 2-aminopy razine.

Product Analysis. The reaction misture in the stoichiometric ratio in presence of $\mathrm{HClO}_{4}$ under stirred condition was allowed to progress for $24 \mathrm{~h}$ at $303 \mathrm{~K}$. After completion of the reaction (monitored by TLC). the reaction mixture was neutralized and the products were extracted with ether. The organic products were subjected to spot tests and chromatograplic analysis (TLC teclunique). The products corresponded to $\mathrm{N}$-oxides as the oxidation products of pyrazines. Pỵrazine-1-oxide. 2-methyylpyrazine-1-oxide. 2-methoxy pyrazine-1-oxide. 2-aminopyrazine1-oxide and 2-ethylpyrazine-1-oxide are the oxidation products of pyrazine. 2-methylpyrazine, 2-methoxypyrazine, 2-aminopy razine and 2-ethylpy razine, respectively. Py razine-1-oxide and 2-methylpyrazine-1-oxide were confirmed by GC-MS analy'sis. GC-MS data was obtained on a 17A Shimadzu gas chromatograph with QP-5050A Shimadzu mass spectrometer. The mass spectra showed a molecular ion peak at 96 and 110 anu clearly confirms pyrazine-1-oxide and 2-methyylpy razine-1oxide, respectively (Figures 1 and 2). All other peaks observed in GC-MS are interpreted in accordance with the observed structure. Pyrazine-N-oxide obtained from pyrazine was extracted with ether and was quantitatively estimated. The recovery of py razine-N-oxide was found to be $72.9 \%$. No further oxidation of these products were observed under the chosen kinetic conditions.

Benzenesulfonamide. a reduction product of $\mathrm{BAB}$. was also extracted with ethyl acetate and identified ${ }^{29}$ by TLC using pet. ether- $\mathrm{CHCl}_{3}-\mathrm{l}$-butanol $(2: 2: 1, \mathrm{v} / \mathrm{v})$ as a solvent system and iodine as a spray reagent $\left(R_{f}=0.88\right)$. It was further confirmed by GC-MS which showed a molecular ion peak of $157 \mathrm{amu}$ (Figure 3).

\section{Results and Discussion}

Kinetic Orders. The kinetics of oxidation of pyrazine and substituted pyrazines by $B A B$ was investigated at several different initial concentrations of the reactants in $\mathrm{HClO}_{4}$ medium. Under comparable experimental conditions. the similar oxidation kinetic behaviour was observed for all the pyrazines studied. The kinetic data obtained are presented in Table 1 .

Effect of Reactant Concentrations on the Rate. Under pseudo first-order conditions of [py razine $]_{C} \gg[\mathrm{BAB}]_{0}$. at constant [pyrazine $]_{\circ} .\left[\mathrm{HClO}_{4}\right]$ and temperature, plots of $\log [\mathrm{BAB}]$ vs. time were linear $(r>0.9904)$, showing a first-order dependence of the rate on $[\mathrm{BAB}]_{\mathrm{c}}$. The values of pseudo first-order rate constants, $k\left(\mathrm{~s}^{-1}\right)$, are given in Table 1 . The values of $k$ remain unaffected with a change in $[\mathrm{BAB}]_{0}$. confirming the first-order 


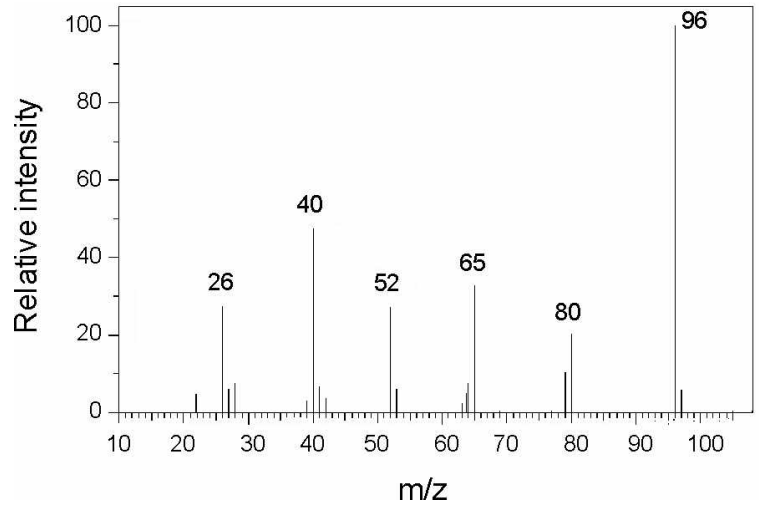

Figure 1. GC-Mass spectrum of pyrazine-N-oxide with its molecular ion peak at 96 amu.

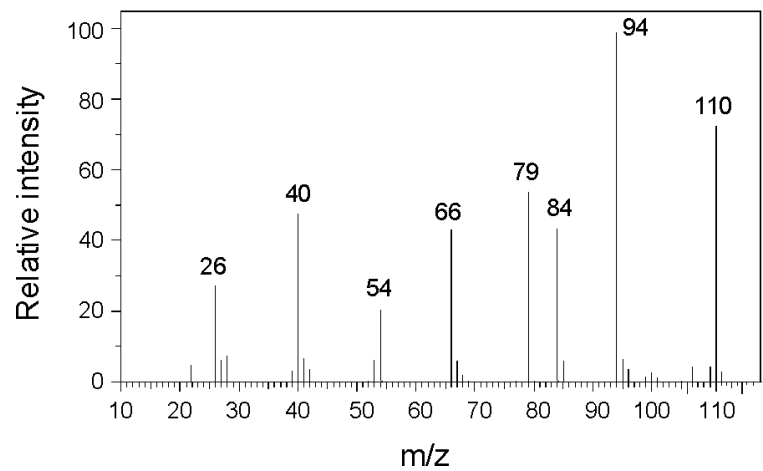

Figure 2. GC-Mass spectrum of 2-methy lpyrazine-N-oxide with its molecular ion peak at 110 annu.

dependence on $[\mathrm{BAB}]_{\mathrm{c}}$. The rate increased with increase in [py razine] (Table 1). Plots of $\log k v s \cdot \log$ [py'razine] were linear $(r>0.9945)$ with unit slopes, indicating the first-order dependence of rate on [pyrazine]. Further plots of $k$ ws. [pyrazine] gave straight lines $(r>0.9802)$ passing through the origin, substantiating a first-order dependence of rate on [py razine]. Furthermore. the second order rate constants $k^{\prime \prime}=k^{\prime} /$

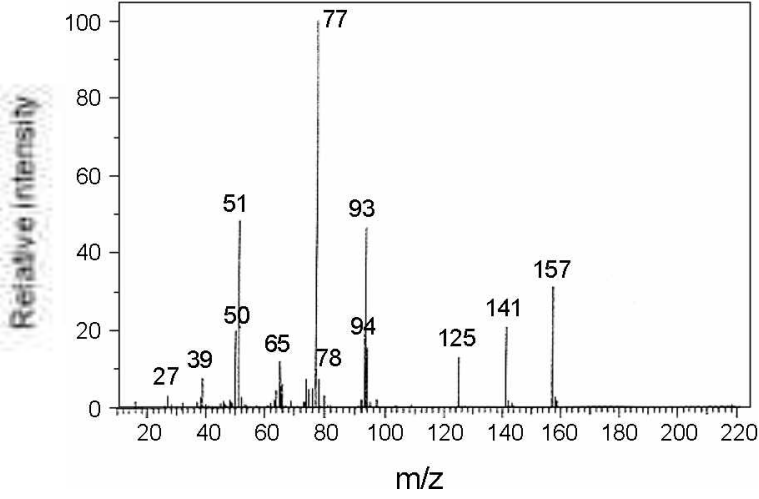

Figure 3. GC-Mass spectrum of tenzenesulfonamide with its molecular ion peak at 157 amu.

[py razine] $]_{i}$ were nearly the same for all the pyrazines except 2-methylpyrazine. establishing the first-order dependence of rate on [py razine] ${ }_{\circ}$ and also the reaction intermediates formed were of transient existence ( $k$ values are not reported).

Effect of $\mathrm{HClO}_{4}$ and Halide Ion Concentrations on the Rate. The reaction rate increased with an increase in $\left[\mathrm{HClO}_{4}\right]$ (Table 1) and plots of $\log k w \cdot \log \left[\mathrm{HClO}_{4}\right]$ were linear $(r>$ $0.9804)$ with fractional slopes $(0.51-0.71)$. showing a fractional-order dependence of the rate on $\left[\mathrm{HClO}_{4}\right]$. Addition of $\mathrm{Br}^{-}$or $\mathrm{Cl}^{-}$ions in the form of $\mathrm{NaBr}$ or $\mathrm{NaCl}\left(5.0 \times 10^{-3} \mathrm{~mol}\right.$ $\mathrm{dm}^{-3}$ ) did not alter the rate of the reaction. suggesting that neither interhalogen nor free bromine was formed during the reaction sequence.

Effect of Benzenesulfonamide and Ionic Strength on the Rate. Addition of benzenesulfonamide $\left(\mathrm{PhSO}_{2} \mathrm{NH}_{2}\right.$ ) to the reaction mixture $\left(5.0 \times 10^{-3} \mathrm{~mol} \mathrm{dm}{ }^{-3}\right)$ had no effect on the rate. This is indicative of non-involvement of $\mathrm{PhSO}_{2} \mathrm{NH}_{2}$ in any step prior to the rate determining in the scheme proposed (Scheme 1). The effect of ionic strength on the reaction rate was carried out in presence of $0.1 \mathrm{~mol} \mathrm{dm}{ }^{-3}$ sodium percllorate, keeping all other experimental conditions constant. It was noticed that the ionic strength had negligible effect on the

Table 1. Effect of Varying BAB, Pyrazine and $\mathrm{HClO}_{4}$ Concentrations on the Reaction Rate at $303 \mathrm{~K}$

\begin{tabular}{|c|c|c|c|c|c|c|c|}
\hline \multirow{2}{*}{$\begin{array}{l}10^{4}[\mathrm{BAB}] \\
\text { mol din }\end{array}$} & \multirow{2}{*}{$\begin{array}{c}10^{3}[\text { pvrazine }] \\
m o l \mathrm{dm}^{3}\end{array}$} & \multirow{2}{*}{$\begin{array}{c}10^{3}\left[\mathrm{HClO}_{4}\right] \\
\mathrm{mol} \mathrm{d}^{3} 2^{3}\end{array}$} & \multicolumn{5}{|c|}{$10^{+} k\left(s^{-1}\right)$} \\
\hline & & & prrazine & 2-methyl pyrazine & 2-ethyl pyrazine & 2-methoxy pyrazine & 2-amino pyrazine \\
\hline 0.5 & 1.8 & 5.0 & $3.90 \pm 0.13$ & $4.86 \pm 0.10$ & $5.72 \pm 0.15$ & $9.11 \pm 0.17$ & $14.4 \pm 0.31$ \\
\hline 1.0 & 1.8 & 5.0 & $3.75 \pm 0.09$ & $4.93 \pm 0.13$ & $5.57 \pm 0.19$ & $906 \pm 0.21$ & $13.9 \pm 0.22$ \\
\hline 1.6 & 1.8 & 5.0 & $3.84 \pm 0.11$ & $4.80 \pm 0.16$ & $5.65 \pm 0.14$ & $9.02 \pm 0.30$ & $14.6 \pm 0.05$ \\
\hline 3.0 & 1.8 & 50 & $3.81 \pm 0.13$ & $4.71 \pm 0.11$ & $5.50 \pm 0.06$ & $909 \pm 0.18$ & $13.7 \pm 0.16$ \\
\hline 5.0 & 1.8 & 5.0 & $3.92 \pm 0.03$ & $4.82 \pm 0.08$ & $5.63 \pm 0.13$ & $8.64 \pm 0.29$ & $15.1 \pm 0.19$ \\
\hline 1.6 & 0.5 & 5.0 & $1.15 \pm 0.05$ & $1.27 \pm 0.21$ & $1.47 \pm 0.05$ & $2.34 \pm 0.03$ & $3.92 \pm 0.02$ \\
\hline 1.6 & 1.0 & 5.0 & $2.01 \pm 0.13$ & $2.45 \pm 0.16$ & $2.80 \pm 0.09$ & $4.90 \pm 0.18$ & $7.41 \pm 0.13$ \\
\hline 1.6 & 1.8 & 5.0 & $3.84 \pm 0.16$ & $4.80 \pm 0.18$ & $5.65 \pm 0.14$ & $9.02 \pm 0.05$ & $14.6 \pm 0.21$ \\
\hline 1.6 & 3.6 & 50 & $7.43 \pm 0.39$ & $9.77 \pm 0.32$ & $10.5 \pm 0.03$ & $17.6 \pm 0.11$ & $29.6 \pm 0.16$ \\
\hline 1.6 & 5.2 & 5.0 & $11.2 \pm 0.03$ & $14.2 \pm 0.09$ & $16.8 \pm 0.08$ & $20.1 \pm 0.14$ & $40.5 \pm 1.62$ \\
\hline 1.6 & 1.8 & 1.0 & $1.20 \pm 0.06$ & $2.06 \pm 0.15$ & $2.93 \pm 0.19$ & $4.03 \pm 0.18$ & $5.63 \pm 0.09$ \\
\hline 1.6 & 1.8 & 2.0 & $1.97 \pm 0.14$ & $2.85 \pm 0.05$ & $3.65 \pm 0.32$ & $6.26 \pm 0.21$ & $9.77 \pm 0.13$ \\
\hline 1.6 & 1.8 & 50 & $3.84 \pm 0.15$ & $4.80 \pm 0.11$ & $5.65 \pm 0.05$ & $9.02 \pm 0.12$ & $14.6 \pm 0.18$ \\
\hline 1.6 & 1.8 & 10.0 & $6.60 \pm 0.15$ & $6.00 \pm 0.12$ & $8.96 \pm 0.16$ & $11.4 \pm 0.15$ & $21.8 \pm 0.21$ \\
\hline 1.6 & 1.8 & 150 & $9.36 \pm 0.21$ & $10.7 \pm 0.17$ & $10.9 \pm 0.22$ & $15.6 \pm 0.08$ & $27.7 \pm 0.15$ \\
\hline
\end{tabular}




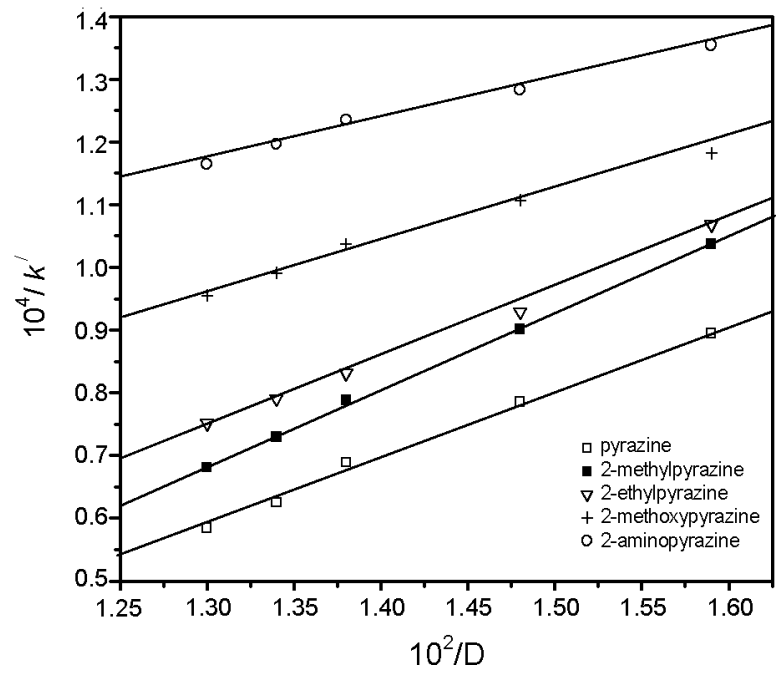

Figure 4. Plots of $\log k$ vs. 1/D. Experimental conditions are as in Table 2 .

reaction rate. suggesting the involvement of non-ionic species in the rate determining step. Subsequently. no attempt was made to keep ionic strength constant during kinetic nuns.

Effect of Dielectric Constant of the Medium on the Rate. In order to find out the nature of reactive species. the dielectric constant (D) of the medium was varied by adding $\mathrm{MeOH}(0$ $30 \% \mathrm{~F} / \mathrm{v}$ ) to the reaction mixture keeping all other experimental conditions constant. The rate increased with increase in $\mathrm{MeOH}$ content (Table 2). Plots of $\log k$ is. $1 / \mathrm{D}$ were linear (Figure 4 : $r>0.9905$ ) with positive slopes. There was no reaction of the dielectric with the oxidant under the prevailing experimental conditions. Values of dielectric constant of $\mathrm{MeOH}-\mathrm{H}_{2} \mathrm{O}$ nixture reported in the literature ${ }^{311}$ were used.

Effect of Solvent Isotope on the Rate. As the rate was dependent on $\left[\mathrm{H}^{-}\right]$, solvent isotope studies were made in $\mathrm{D}_{2} \mathrm{O}$ medium with pyrazine as a probe. Values of $k\left(\mathrm{H}_{2} \mathrm{O}\right)$ and $k\left(\mathrm{D}_{2} \mathrm{O}\right)$ were $3.84 \times 10^{-4}$ and $4.70 \times 10^{-4} \mathrm{~s}^{-1}$, respectively, giving a solvent isotope effect. $k\left(\mathrm{H}_{2} \mathrm{O}\right) / k\left(\mathrm{D}_{2} \mathrm{O}\right)=0.82$

Effect of Temperature on the Rate. The effect of temperature on the rate was studied by conducting the kinetic experiments at $293.298,303,308$ and $313 \mathrm{~K}$. keeping other experimental conditions constant. From the linear Arrhenius plots of $\log k$ is. $\mathrm{I} / \mathrm{T}(r>0.9907)$, activation parameters $\left(\mathrm{E}_{\mathrm{a},}, \mathrm{HH}^{\ddagger}, \Delta \mathrm{S}^{\ddagger}, \Delta \mathrm{G}^{\ddagger}\right.$ and $\log$ A) for the overall reaction were computed and the results are summarized in Table 3.

Polymenzation Study. Addition of the reaction mixture to the acrylamide monomer did not initiate polymerization indicating the absence of any free radicals produced during the course of reaction.

Reactive Species of BAB. Organic haloamines have homogeneous chemical properties and hence it is expected that similar equilibria exist in solutions of these conpounds. ${ }^{28,31 \cdot-23}$ Bromamine-B, which is analogous to chloramine- $T$ and chloranine-B. behaves like a strong electrolyte both in acidic and alkaline media. ${ }^{31}$ The oxidation potential of $\mathrm{BAB} / \mathrm{PhSO}_{2} \mathrm{NH}_{2}$ is $\mathrm{pH}$ dependent ${ }^{2}$ and decreases with increase in the $\mathrm{pH}$ of the medium $(\mathrm{L}+\mathrm{V}$ at $\mathrm{pH} 0.65$ and $0.50 \mathrm{~V}$ at $\mathrm{pH} 12.0$ ). In acid solutions. $\mathrm{BAB}$ exists in the following equilibria:

$$
\begin{aligned}
& \mathrm{PhSO}_{2} \mathrm{NBrNa} \rightleftharpoons \mathrm{PhSO}_{2} \mathrm{NBr}^{-}+\mathrm{Na}^{-} \\
& \mathrm{PhSO}_{2} \mathrm{NBr}^{-}+\mathrm{H}^{+} \rightleftharpoons \mathrm{PhSO}_{2} \mathrm{NHBr}
\end{aligned}
$$

Table 2. Effect of Varying Dielectric Constant (D) of Medium on the Reaction Rate at $303 \mathrm{~K}$

\begin{tabular}{ccccccc}
\hline \multirow{2}{*}{$\% \mathrm{CH}_{3} \mathrm{OH} v / \mathrm{v}$} & $\mathrm{D}$ & \multicolumn{5}{c}{$10^{4} k\left(\mathrm{~s}^{\circ}\right)$} \\
\cline { 3 - 7 } & & pyrazine & 2-methyl pyrazine & 2-ethyl pyrazine & 2-methoxy pyrazine & 2-amino pyrazine \\
\hline 0 & 76.7 & $3.84 \pm 0.08$ & $4.80 \pm 0.18$ & $5.65 \pm 0.06$ & $9.02 \pm 0.07$ & $14.6 \pm 0.19$ \\
5 & 74.5 & $4.22 \pm 0.06$ & $5.36 \pm 0.12$ & $6.18 \pm 0.08$ & $9.80 \pm 0.16$ & $15.7 \pm 0.21$ \\
10 & 72.4 & $4.89 \pm 0.12$ & $6.14 \pm 0.03$ & $6.78 \pm 0.05$ & $10.8 \pm 0.15$ & $17.2 \pm 0.32$ \\
20 & 69.7 & $6.10 \pm 0.05$ & $7.98 \pm 0.16$ & $8.50 \pm 0.06$ & $12.8 \pm 0.38$ & $19.2 \pm 0.15$ \\
30 & 67.5 & $7.85 \pm 0.31$ & $10.9 \pm 0.19$ & $11.7 \pm 0.18$ & $15.2 \pm 0.24$ & $22.6 \pm 0.28$ \\
\hline
\end{tabular}

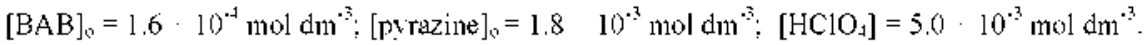

\begin{tabular}{|c|c|c|c|c|c|}
\hline \multirow{2}{*}{ Temperature $\mathrm{K}$} & \multicolumn{5}{|c|}{$10^{+} k\left(s^{\circ}\right)$} \\
\hline & pyrazine & 2-methyl pyrazine & 2-ethyl pyrazine & 2-methoxy pyrazine & 2-amino pyrazine \\
\hline 293 & $1.93 \pm 0.05$ & $2.35 \pm 0.06$ & $3.03 \pm 0.07$ & $5.76 \pm 0.16$ & $9.95 \pm 0.30$ \\
\hline 298 & $2.60 \pm 0.07$ & $3.20 \pm 0.08$ & $4.41 \pm 0.11$ & $7.61 \pm 0.25$ & $11.0 \pm 0.25$ \\
\hline 303 & $3.84 \pm 0.09$ & $4.80 \pm 0.16$ & $5.65 \pm 0.15$ & $9.02 \pm 0.18$ & $14.6 \pm 0.30$ \\
\hline 308 & $5.23 \pm 0.17$ & $6.85 \pm 0.24$ & $7.80 \pm 0.14$ & $11.2 \pm 0.37$ & $18.2 \pm 0.36$ \\
\hline 313 & $8.29 \pm 0.25$ & $8.98 \pm 0.23$ & $10.1 \pm 0.35$ & $14.3 \pm 0.34$ & $21.6 \pm 0.47$ \\
\hline $\mathrm{E}_{\mathrm{a}}\left(\mathrm{k}_{\mathrm{T}} \mathrm{T} \mathrm{mol} \mathrm{l}^{-1}\right)$ & 58.2 & 55.7 & 48.7 & 33.4 & 27.7 \\
\hline$\Delta \mathrm{H}^{\mp}\left(\mathrm{kJ}_{\mathrm{J}} \mathrm{mol} \mathrm{l}^{-\mathrm{l}}\right)$ & $55.7 \pm 0.02$ & $51.7 \pm 0.14$ & $460 \pm 0.14$ & $309 \pm 0.01$ & $25.1 \pm 0.01$ \\
\hline$\Delta G^{2}\left(\mathrm{k}^{\mathrm{K}} \mathrm{\top} \mathrm{mol}^{-1}\right)$ & $94.0 \pm 0.26$ & $93.6 \pm 0.18$ & $93.0 \pm 1.20$ & $94.0 \pm 0.51$ & $90.7 \pm 0.35$ \\
\hline$\Delta \mathrm{S}^{-}\left(. \mathrm{K}^{-1} \mathrm{~mol}^{-1}\right)$ & $-127 \pm 0.20$ & $-146 \pm 0.08$ & $-155 \pm 0.10$ & $-201 \pm 0.37$ & $-216 \pm 0.11$ \\
\hline $\log A$ & 110 & 9.71 & 100 & 6.64 & 606 \\
\hline
\end{tabular}

Table 3. Effect of Varying Temperature on the Reaction Rate and Activation Parameters for the Oxidation of Py razines by BAB in Acid Medium

$[\mathrm{BAB}]_{0}=1.6 \cdot 10^{-4} \mathrm{~mol} \mathrm{dm}{ }^{-3} ;[\text { prazine }]_{0}=1.8 \quad 10^{\cdot 3} \mathrm{~mol} \mathrm{dm}^{\cdot 3} ;\left[\mathrm{HClO}_{4}\right]=5.0 \cdot 10^{-3.3} \mathrm{~mol} \mathrm{dm}^{\cdot 3}$. 


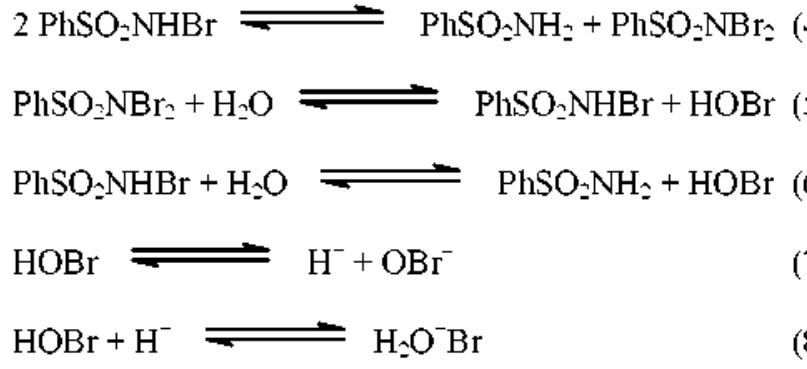

The possible oxidizing species in acidified $\mathrm{BAB}$ solutions are therefore the free acid ( $\mathrm{PhSO} 2 \mathrm{NHBr}$ ). dibromamine-B $\left(\mathrm{PhSO}_{2} \mathrm{NBr}_{-}\right)$, hypobromous acid $(\mathrm{HOBr})$ and possibly $\mathrm{H}_{2} \mathrm{O}^{-} \mathrm{Br}$. The involvement of $\mathrm{PhSO}_{2} \mathrm{NBr}_{2}$ in the mechanism should correspond to a second-order rate law, which is contrary to the experimental observations. If $\mathrm{HOBr}$ were the primary oxidizing species, a first-order retardation of the rate by the added benzenesulfonamide would be expected which is contradictory to the observed experimental results. Since pKa of $\mathrm{PhSO}_{2} \mathrm{NHBr}$ is 4.95 at $298 \mathrm{~K}$. it is likely that under the present acidic conditions $\mathrm{BAB}$ may exist ${ }^{32}$ primarily as $\mathrm{PhSO}_{2} \mathrm{NHBr}$ and any dependence of rate on $\left[\mathrm{H}^{+}\right]$could be attributed to the addition of a second proton to $\mathrm{PhSO}_{2} \mathrm{NHBr}$. Furthermore Narayanan and $\mathrm{Rao}^{34}$ and Sublhashini et al ${ }^{35}$ have reported that monochloramines can be further protonated at $\mathrm{pH} 2$ as shown in eq. (9) and eq. (10) for chloramine-T and clloramine-B. respectively.

$$
\begin{aligned}
& \mathrm{p}-\mathrm{CH}_{3} \mathrm{C}_{6} \mathrm{H}_{4} \mathrm{SO}_{-} \mathrm{NHCl}+\mathrm{H}^{+} \rightleftharpoons\left(\mathrm{p}_{-} \mathrm{CH}_{3} \mathrm{C}_{6} \mathrm{H}_{4} \mathrm{SO}_{-} \mathrm{NH}_{2} \mathrm{Cl}\right)^{-} \\
& \mathrm{PhSO}_{2} \mathrm{NHCl}+\mathrm{H}^{+} \rightleftharpoons\left(\mathrm{PhSO}_{2} \mathrm{NH}_{2} \mathrm{Cl}\right)^{-}
\end{aligned}
$$

The second protonation constants for $\mathrm{CAT}$ and $\mathrm{CAB}$ are $102 \mathrm{M}^{-1}$ and $61 \pm 5 \mathrm{M}^{1}$ respectively at $298 \mathrm{~K}$. Because organic haloamines have similar chemical properties. it is reasonable to expect the formation of an identical species of the type $\mathrm{PhSO}_{2} \mathrm{NH}_{2} \mathrm{Br}^{-}$for $\mathrm{BAB}$ also. In the present investigations. the acceleration of rate by $\mathrm{H}^{-}$ion indicates that $\mathrm{PhSO}_{2} \mathrm{NH}_{2} \mathrm{Br}^{-}$is the active oxidizing species. Further. variations of ionic strength of the medium or addition of the reaction product. benzenesulfonamide have virtually no effect on the rate. Based on the preceding discussion and experimental facts. Scheme 1 is proposed to explain the reaction mechanism for the oxidation of pyrazines by $\mathrm{BAB}$ in $\mathrm{HClO}_{+}$medium.

A detailed mode of oxidation of pyrazines by $\mathrm{BAB}$ in acid medium and the structure of intermediate are depicted in Scheme 2. In Scheme 2, an initial equilibrium involves protonation of $\mathrm{PhSO}_{2} \mathrm{NHBr}$ forming the active oxidizing species of $\mathrm{BAB}$. $\mathrm{PhSO}_{2} \mathrm{NH}_{2} \mathrm{Br}^{+}$(step (i)). In the next slow/rate determining step (step (ii)). nucleophilic attack on the positive bromine of $\mathrm{PhSO}_{2} \mathrm{NH}_{2} \mathrm{Br}^{+}$by a lone pair of electrons on nitrogen atom of py razine. results in the formation of a complex cation $X$ with the elimination of $\mathrm{PhSO}_{2} \mathrm{NH}_{2}$. In the next step (step (iii)). followed by several fast steps. the complex cation $\mathrm{X}$ undergoes hydrolysis leading to the formation of $\mathrm{N}$-oxide with the elimination of $\mathrm{HBr}$.

If $[B A B]_{t}$ is the total effective concentration of $\mathrm{BAB}$. then

$$
[\mathrm{BAB}]_{\mathrm{t}}=\left[\mathrm{PhSO} \mathrm{NHBr}_{-}\right]+\left[\mathrm{PhSO}_{-} \mathrm{NH}_{2} \mathrm{Br}^{+}\right]
$$

$$
\begin{aligned}
& \mathrm{PhSO}_{2} \mathrm{NHBr}+\mathrm{H}^{-} \stackrel{K_{l}}{=} \mathrm{PhSO}_{2} \mathrm{NH}_{2} \mathrm{Br}^{-} \quad \text { (i) fast } \\
& \mathrm{PhSO}_{2} \mathrm{NH}_{2} \mathrm{Br}^{+}+\text {Pyrazine } \stackrel{k_{2}}{\longrightarrow} \mathrm{X}+\mathrm{PhSO}_{2} \mathrm{NH}_{2} \text { (ii) slow } \\
& \mathrm{X}+\mathrm{H}_{2} \mathrm{O} \longrightarrow \text { Products }+\mathrm{HBr}_{3} \quad \begin{array}{l}
\text { and rds } \\
\text { (iii) fast }
\end{array}
\end{aligned}
$$

Scheme 1. A general reaction scheme for the oxidation of pyrazine and 2-substituted pyrazines by $\mathrm{BAB}$ in $\mathrm{HClO}_{4}$ medium

$$
\mathrm{PhSO}_{2} \mathrm{NHBr}+\mathrm{H}^{+} \stackrel{K_{1}}{\rightleftharpoons} \mathrm{PhSO}_{2} \stackrel{+}{\sim} \mathrm{H}_{2} \mathrm{Br}
$$

(ii)


(Pyrazine)

$(\mathrm{X})$

(iii)

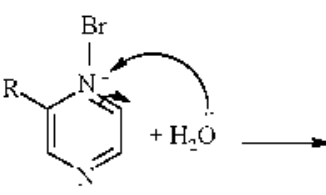<smiles>[R]C1=CN=CC[N+]1(O)O[GaH]</smiles>

(X)<smiles>[R]C1=CN=C[C-](CC)N1</smiles><smiles></smiles>

Scheme 2. Detailed mechanistic interpretation for the oxidation of pyrazines by $\mathrm{BAB}$ in acid medium

From steps (i) and (ii) of Scheme 1, the following rate law (12) is obtained.

$$
\text { rate }=\frac{K_{1} k_{2}[\mathrm{BAB}]_{\mathrm{t}}[\text { pyrazine }]\left[\mathrm{H}^{+}\right]}{1+K_{l}\left[\mathrm{H}^{-}\right]}
$$

Rate law (12) is in good agreement with the experimental results. wherein a first-order dependence each on $[\mathrm{BAB}]_{\circ}$ and [pyrazine $]_{1}$. and fractional-order on $\left[\mathrm{H}^{+}\right]$was observed.

Since. rate $=k[\mathrm{BAB}]_{\mathrm{t} .}$ eq. (12) can be transformed as:

$$
\begin{aligned}
& k=\frac{K_{1} k_{2} \text { [pyrazine }\left[\mathrm{H}^{+}\right]}{1+K_{1}\left[\mathrm{H}^{-}\right]} \\
& \frac{1}{k^{\prime}}=\frac{1}{K_{1} k_{2} \text { [pyrazine] }\left[\mathrm{H}^{+}\right]}+\frac{1}{k_{2}[\text { pyrazine }]}
\end{aligned}
$$

Based on eq. (14). plots of $1 / k$ vs. $1 /\left[\mathrm{H}^{-}\right]$(values are taken from Table $\mathrm{l}$ ) at constant $[\mathrm{BAB}]_{\mathrm{C}}$. [pyrazine] $]_{\mathrm{c}}$ and temperature 


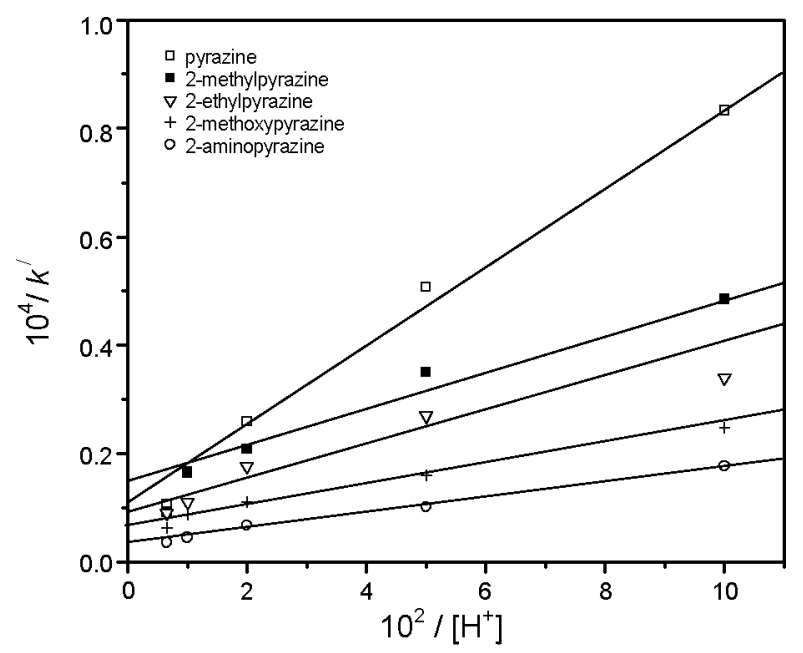

Figure 5. Double reciprocal plots of $1 / \hbar$ is. $1 /\left[\mathrm{H}^{+}\right]$. Experimental conditions are as in Table 1

has been found to be fairly linear (Figure $5: r>0.9576$ ) for each py razine. The protonation constants $\left(K_{i}\right)$ of $\mathrm{PhSO}_{-} \mathrm{NHBr}$ and the decomposition constant $\left(k_{2}\right)$ were calculated from slope and intercept of these plots for the standard run with $[\mathrm{BAB}]_{0}=1.6 \times 10^{-4} \mathrm{~mol} \mathrm{dm}^{-3}:$ [py razine $]_{0}=1.8 \times 10^{-3} \mathrm{~mol}$ $\mathrm{dm}^{-3}$ at $303 \mathrm{~K}$. Further the values of deprotonation constant. $K_{i}=1 / K_{i}$ were also determined. All these values are presented in Table 4 . The proposed mechanism and the rate law derived are supported by the experimental findings given below:

Solvent Isotope Effect. Reactions in aqueous medium that are susceptible to acid-base catalysis have been studied in heavy water $\left(D_{2} O\right)$ after equilibrium. Since most oxidation reactions of organic compounds involve the cleavage of $\mathrm{C}-\mathrm{H}$ bond deuterium isotope effect on such reactions gives information regarding the nature of the rate determining step. In the present investigations. solvent isotope studies have shown that the rate of reaction is higher in $\mathrm{D}_{-} \mathrm{O}$ medium. For a reaction involving a fast equilibrium $\mathrm{H}^{-}$or $\mathrm{OH}^{-}$ion transfer the rate increases in $\mathrm{D}_{2} \mathrm{O}$ medium since $\mathrm{D}_{3} \mathrm{O}^{-}$or $\mathrm{OD}^{-}$are a stronger acid and a stronger base. respectively than $\mathrm{H}_{3} \mathrm{O}^{-}$and $\mathrm{OH}^{-}$ions. ${ }^{36}$. ${ }^{37}$ The observed solvent isotope effect of $k\left(\mathrm{H}_{2} \mathrm{O}\right) / k\left(\mathrm{D}_{2} \mathrm{O}\right)<$ $\mathrm{I}$ is due to the greater acidity of $\mathrm{D}_{3} \mathrm{O}^{+}$compared to $\mathrm{H}_{3} \mathrm{O}^{+}$. However. the magnitude of increase in rate in $\mathrm{D}_{2} \mathrm{O}$ is small (expected value is $2-3$ times greater). This may be due to the fractional order dependence of rate on $\left[\mathrm{H}^{-}\right]$. Hence. this observation supports the proposed mechanism.

Dielectric Constant Effect. A change in solvent composition by varying methanol content affects the reaction rate. The effect of solvent on the reaction kinetics has been described in detail in the well-known monographs of Moelwy'n-Hughes. ${ }^{38}$ Benson. ${ }^{34}$ Frost and Pearson, ${ }^{\text {th }}$ Laidler ${ }^{41}$ and Amis. ${ }^{+2}$ For the limiting case of zero angle of approach between two dipoles or an ion-dipole system, Amis ${ }^{t z}$ has shown that a plot of $\log k$ vis. 1/D gives a straight line with a negative slope for a reaction involving a negative ion and a dipole or between the dipoles. while a positive slope results for a positive ion-dipole interaction. The latter argument agrees with the observed results. where. a positive ion and a dipole are involved in the rate determining step of Scheme 2 .
Table 4. Values of Protonation, Decomposition and Deprotonation Constants for the Oxidation of Pyrazine by BAB in Acid Medium at $303 \mathrm{~K}$

\begin{tabular}{lccc}
\hline & $\begin{array}{c}10^{-2} K_{1} \\
\left(\mathrm{dm}^{3} \mathrm{~mol}^{-1}\right)\end{array}$ & $k_{2}\left(\mathrm{~s}^{-1}\right)$ & $\begin{array}{c}10^{2} \mathrm{~K}_{1}^{*} \\
\left(\mathrm{~mol} \mathrm{dm}^{-3}\right)\end{array}$ \\
\hline pyrazine & 0.93 & 0.79 & 1.07 \\
2-methylpyrazine & 0.77 & 0.85 & 1.29 \\
2-ethylpyrazine & 1.30 & 0.79 & 0.76 \\
2-methosypyrazine & 1.75 & 0.85 & 0.57 \\
2-aminopyrazine & 0.94 & 1.98 & 1.06 \\
\hline [BAB] $]_{0}=1.6 \cdot 10^{-4} \mathrm{~mol} \mathrm{dm}^{-3}:[\text { [pyrazine }]_{0}=1.8 \cdot 10^{-3} \mathrm{~mol} \mathrm{dm}^{-3}:\left[\mathrm{HClO}_{4}\right]=$ \\
$5.0 \cdot 10^{-3} \mathrm{~mol} \mathrm{dm}^{-3}$.
\end{tabular}

Structure Reactivity Comelation Structural modification of a reactant molecule may influence the rate or equilibrium constant of a reaction through inductive, polar, steric and resonance effects which can be used to probe into the reaction mechanism. Out of a number of entirical models proposed in describing the relationships between structure and reactivity, the most successful and extensively investigated are the linear free energy relationships ${ }^{43}$ with the Hammett equation as the most prominent example. The Hammett treatment describes the substituent effects on rate and equilibria of aromatic molecules. In the present system. structure reactivity relationship is ascertained by utilizing different groups at the second position of the pyrazine ring and tested to fit into the results to the Hammett equation. ${ }^{+1}$ The Hammett plot $(\log k v s . \sigma)$ is reasonably linear $(r=0.98+6)$. From a plot of $\log k$ vs. $\sigma$. the value of the reaction constant $\rho$ is found to be -0.8 signifying that the electron releasing groups in the py razine ring enlances the rate. The negative $\rho$ value implies the formation of cationic transition state $X$ (Scheme 2). The positive inductive effect of the substituents increases the electron density at nitrogen of pyrazine and subsequently the lone pair of electrons of nitrogen of pyrazine easily attacks the positive bromine of reactive oxidizing species to form cationic transition state. Further, the positive inductive effect of the substituents in the present system increases in the order $-\mathrm{NH}_{2}>-\mathrm{OCH}_{3}>-\mathrm{C}_{2} \mathrm{H}_{5}>-\mathrm{CH}_{3}>$ $\mathrm{H}$. which justified by the observed reactivity trend: 2 -aminopy razine $>2$-methoxypyrazine $>2$-ethylpy razine $>2$-methy $1-$ py razine $>$ py razine for pyrazines oxidations.

Isoldinetic Relationship. The activation energy is highest for the slowest reaction (Table 3) indicating that the reaction is enthalpy controlled. Within a reaction series. the variation in the rate may be caused by changes in either the enthalpy or the entropy of activation or both. Among the recognized categories, changes in rate are caused by changes in both enthalpy and entropy of activation quantities in a parallel fashion is one of the important categories. In this class. enthalpy and entropy of activation are correlated by linear relationship $\Delta \mathrm{H}^{ \pm}=\Delta \mathrm{H}^{2}{ }_{0}+$ $\beta\lrcorner S^{*}$. which is called the isokinetic relationship ${ }^{45}$ and $\beta$ is the isokinetic temperature. When the experimental tenmerature $\mathrm{T}<$ $\beta$. the reaction rate is controlled mainly by the enthalpy change. In the present case, the enthalpies and entropies of activation for the oxidation of the pyrazines are linearly related by plotting $\triangle \mathrm{H}^{*}$ vs. $\lrcorner \mathrm{S}^{*}$ (Figure 6: $r=0.9920$ ). From the slope. the value of isokinetic temperature ( $\beta$ ) is computed and found to 


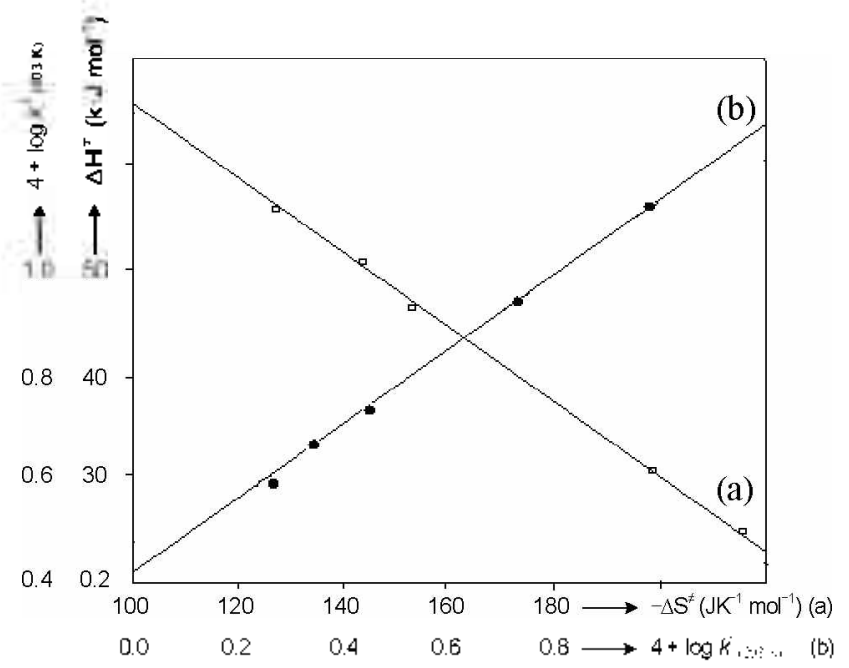

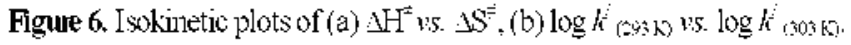
Experimental conditions are as in Table 3 .

be $333 \mathrm{~K}$. The isokinetic temperature can also be obtained from a log-log plot of rate constants at the two different temperatures as suggested by Exner. ${ }^{+6}$ Accordingly. in the present investigation a plot of $\log k_{293} \mathrm{~K}, \mathrm{vs} \cdot \log k_{i 3(3 \mathrm{~K})}$ is a straight line (Figure $6: r=0.9936$ ). The value of $\beta$ was calculated from the equation $\beta=T_{1}(1-q) /\left(T_{1} / T_{2}-q\right)$, where $q$ is the slope of the Exner plot: $\beta$ was found to be $331 \mathrm{~K}$. The values of $\beta$ calculated from both plots are higher than the experimental temperature of $303 \mathrm{~K}$. This suggests that the reaction is enthalpy controlled. The existence of isokinetic relationship is of signficance and is very valuable to the mechanistic chemist when used as supportive evidence along with other types of data. The large negative values of $\Delta \mathrm{S}^{\dot{x}}$ indicate a more ordered activated complex and the near constancy of $\triangle \mathrm{G}^{ \pm}$shows an identical mechanistic pathway in the oxidation of all the py razines studied. Further, the independent nature of the rate towards the addition of benzenesulfonamide. halide ions and neutral salts substantiates the proposed mechanism and the rate law derived.

\section{Summary}

The kinetics of oxidation of py razine and substituted pyrazines to the respective pyrazine- $\mathrm{N}$-oxides by $\mathrm{BAB}$ has been studied at $303 \mathrm{~K}$. The oxidation reaction follow's the identical kinetic characteristics for all the pyrazines and obey's the rate law: rate $=\mathrm{k}[\mathrm{BAB}]_{0}$, [py razine $]_{0}\left[\mathrm{H}^{+}\right]^{\mathrm{x}}$, where $\mathrm{x}$ is less than unity. The rate of oxidation of py razines increased in the order: 2-aminopyrazine $>2$-methoxỵ pyrazine $>2$-ethỵlpy razine $>$ 2-methylpy razine $>$ pyrazine. The Hammett relationship is observed for the reaction with $p=-0.8$. showing that the electron donating groups enlhance the rate. Activation parameters and isokinetic temperature were deduced. On the basis of experimental results. a suitable mechanism and appropriate rate law have been worked out.

Acknowledgments. Authors thank the Reviewers. Prof. B.S. Sheshadri and Prof. M. A. Pasha for valuable suggestions.

\section{References}

1. Campbell, M. M.; Jolu1son, G. Chent. Rev, 1978, 78, 65.

2. Murthy, A. R. V.: Rao, B. S. Proc Indian Acad. Sci. 1952, 35, 69

3. Baneñi, K. K. Jayaram, B.: Mahadevappa, D. S. J. Sci. Ind. Res. $1987,+6.65$.

4. Brenner, D. H. In. Sinth. Reagents 1985, 6,9.

5. Gowda, B. T.; Mahadevappa, D. S. J Chem. Soc. Perhin Trans. II 1983,323

6. Geethanjali, A. Swlett. 2005, $18,2857$.

7. Kolvari, E.; Ghorbani-Choghamarani, A.; Salehi, P; Shirini, F; Zolfigol, M. A. J. Iron. Chem. Soc 2007, t, 126 .

8. Puttaswamy .: Mahadevappa, D. S.: Rangappa, K. S. Bull. Chem. Soc. Japan 1989, 62, 3343.

9. Ananda, S.; Jagadeesha, M. B.; Puttaswamy:- Venkatesha, B. M: Vinod, T. K. Gowda, N. M M Int. J. Chent Kinet. 2000, 32, 776.

10. Shashikala, V.; Rangappa, K. S. J. Carbohy Chem. 2002, 21, 219.

11. Puttaswamy: Tagadeesh, R. V. Appl Catal .4: Gen 2005, $292,259$.

12. Meenakshisundaram, SP.; Markkandan, R. Indian J. Chent. 2005, HA, 71 .

13. Usha, K. M.; Gowda, B. T. J. Che. Sci. 2006, 118, 351

14. Vasudha, A. M Stnicnireal tspects of Psendononatic Compoumds; University of Poona: Poona, 1966; p 10.

15. Andrew, T. T.; Mottaram, D. S. Flavor Science: Recent Developments; Woodhead Publishing: Great Britain, 1996; p 202.

16. Fenrema, O. R. Food Chemism: Marcel Dekker: The Ohio State Univer, Colombus, Ohio, 1996; p 741

17. Brown, D. T. The Pyrazines, Tohn-Wiley Interscience: New-York, 2002; 77

18. Borg-Karlson, A. K.; Tengo, J. J. Chem. Ecolog, 1980, 6, 827

19. Joule, T. A : Mills, K. Heterocyclic Chemism: Wiley-Blackwell: New-York, 2002; p 194.

20. Craig, E. M.; Garth Pews, R. J. Org. Chent. 1977, 42, 1869.

21. Nobuhiro, S. J. Org. Chem. 1978, 43,3367.

22. Seizaburo, O: Alira K : Tsuneo, K: Fumihiko, U. Chem Pham Bull. $1971,19,1344$

23. Elina, A. S.; Musatova, I. S.; Syrova, G. P. Khim. Getero. Soed. $1968+725$.

24. Klein, B.; Berkowitz, J. J. Am. Chem. Soc. 1959,81,5160

25. Langmuir, V. K.: Laderoute, K. R.; Mendonca, H. L ; Sutherland, R. M.;Hei, T. K.; Liu, S. X; Hall, E. J; Naylor, M. A; Adams, G. E. Int. J. Radiat Oncol. Biol Phy 1996, 3+ 79

26. Hei, T. K.: Lilu, S. X.; Hall, E. T. Br. J. Cancer Suppl 1996, 7, 57.

27. Alumed, M. S.; Mahadevappa, D. S. Talanta 1980, $27,669$.

28. Morris, J. C.: Salazar, I. A.: Wineman, M. A.J. Am. Chem. Soc. $19+8,70,2036$

29. Puttaswany -; Nimala Vaz. Tronsition Het. Chem. 2003, $28,409$.

30. Akerloff, G. J .1m Chem. Soc. 1932, 54, 4125.

31. Bishop, E.: Tennings, V. J. Talanta 1959, 1, 197.

32. Hardy, F. F. Tolunston, J. P.J. Chent. So. Perkin Trons II 1973, 742.

33. Pry de, B. G.: Soper, F. G. J. Chent Soc. $1962,1582$.

34. Narayanan, S. S.; Rá, V. R. S. Radio Chim Acta 1983, 32, 211

35. Subhashini. M: Subramanian M: Reb. V. R S. Talanta 1985, 32, 1082

36. Collins, C. . . Bowman, N. S. Isotope Effects in Chemical Reactions, Van Nostrand Reinhold, New York, 1970; 1267.

37. Kohen, A.: Limbach, H. H. Isptope Effects in Chemisty and Biologn' CRC Press: Florida, $2006 ;$ p 827.

38. Moelwyn-Hughes, E. A. The Kinetics of Reaction in Solutions; Clarender Press: Oxford, 1947; p 374.

39. Benson, S. W. The Foundations of Chemical Kinetics: McGrawHill: New York, 1960: p 19

40. Frost, A. A.; Pearson, R. G. Kinetics and Mechanism: Wiley: New York, 1961:p 135

41. Laidler, K. J. Chentcol Kinetics; Tata Mc Graw-Hill: New Delhi, $1995, \mathrm{p} 211$

42. Amis, E. S. Solvent Effects on Reaction Rates and Mechanisms; Academic Press: New York, 1966; p 1672

43. Gilliom, R. D. Introduction to Phssical Onganic Chentism, AddisonWesley: London, 1970; p 144.

44. Hammett, L. P. J. Am Chem. Soc. 1937, 59, 96.

45. Exner, O Coll Czech Chem Commum 1964. 29, 1094.

46. Exner, O. Pro. Phy Org. Chent 1973, 10,411. 